\title{
Mersin İlinde Bazı Önemli Sebzelerin Karlılığı
}

\author{
The Profitability Analysis of the Main Vegetables in Mersin Province
}

\section{Seyit HAYRAN*}

Çukurova Üniversitesi, Ziraat Fakültesi, Tarım Ekonomisi Bölümü, 01330, Adana

shayran@cu.edu.tr

(iD) 0000-0002-0223-8034

\section{Aykut GÜL}

Çukurova Üniversitesi, Ziraat Fakültesi, Tarım Ekonomisi Bölümü, 01330, Adana

aykutgul@cu.edu.tr

(iD) 0000-0002-8708-8433

*Sorumlu yazar

Gönderilme Tarihi : 24 Mart 2020

Kabul Tarihi : 6 Haziran 2020

\section{ÖZET}

Bu çalışmada, Mersin İlinde örtü altında yetiştirilen domates, biber, patlıcan, hıyar, kabak ve fasulye üretiminin maliyet ve kârlılık göstergelerinin hesaplanması amaçlanmıştır. Araştırmada sebzelerin maliyet, brüt kar, net kar ve nispi kar göstergeleri hesaplanmıştır. Araştırma verileri 2019 yılına aittir. Yapılan hesaplama sonucunda 2019 yılında domates, biber, patlican, hiyar, kabak ve fasulye maliyetleri sirasiyla 0,81 TL/kg, 3,06 TL/kg, 1,79 TL/kg, 0,88 TL/kg, 2,07 TL/kg ve 1,06 TL/kg olarak hesaplanmıştır. İncelenen ürünlerin kârlılıklarının karşılaştırılması, brüt kâr, net kâr ve nispi kâr hesaplanarak yapılmıştır. Araştırma sonuçlarına göre, Mersin İlinde üretimi yapılan domates, biber, patlıcan, hıyar, kabak ve fasulyenin çiftçiye sağladıkları net gelir ve diğer kârlılık göstergeleri bakımından tercih edilebilir ürünler olduğu belirlenmiştir.

Anahtar Kelimeler: Maliyet, Brüt Kâr, Kârlılık, Örtüaltı Tarım, Mersin 
Abstract: In this study, it is aimed to calculate the cost and profitability indicators of tomato, pepper, eggplant, cucumber, pumpkin and bean production grown under cover in Mersin Province. In the research, cost, gross profit, net profit and relative profit indicators of vegetables were calculated. Research data belongs to 2019 . As a result of the calculation, costs of tomato, pepper, eggplant, cucumber, pumpkin, and bean were $0.81 \mathrm{TL} / \mathrm{kg}, 3.06 \mathrm{TL} / \mathrm{kg}, 1.79 \mathrm{TL} / \mathrm{kg}, 0.88$ $\mathrm{TL} / \mathrm{kg}, 2.07 \mathrm{TL} / \mathrm{kg}$ and $1.06 \mathrm{TL} / \mathrm{kg}$, respectively, in 2019. A comparison of the profitability of the examined products was made by calculating gross profit, net profit, and relative profit. According to the results of the research, it has been determined that tomato, pepper, eggplant, cucumber, zucchini and bean are preferred products in terms of net income and other profitability indicators in Mersin.

Keywords: Cost, Gross Profit, Profitability, Greenhouse, Mersin

\section{GİRIŞ}

Tarım sektörü, gerek insan beslenmesi ve gerekse diğer sektörlere hammadde ve sermaye aktarımı bakımından tüm dünyada olduğu gibi Türkiye'de de önemli bir sektördür (Dinler, 2014). Tarım ve gida sektöründe fiyat oluşumu, özellikle son zamanlarda, son derece önem taşır hale gelmiştir. Tarım ve gıda ürünlerinin fiyat oluşumunda, tarımsal ürünlerin maliyet yapılarının ortaya konulması ve üreticinin kârlılık düzeyinin belirlenmesi önemlidir. Tarımsal ürünlerinin maliyetlerinin hesaplanmasında ise üretim sürecinde kullanılan üretim faktörlerinin bir dekar için harcanan miktarlarının parasal karşılığının tespit edilmesi, satış fiyatının oluşumunda önemli bir ölçüttür (Kıral ve ark, 1999). Bu çalışmada, Türkiye'de örtü altı tarımda önemli bir yer tutan Mersin İlinde yetiştirilen en önemli tarımsal ürünler olan domates, biber, patlıcan, hıyar, kabak ve fasulyenin maliyet ve kârlılıklarının saptanması amaçlanmıştır. Söz konusu ürünler, Mersin İlinde örtü altı tarımında en fazla üretimi yapılan sebzelerdir. Türkiye'de 2019 y1lı itibariyle örtü altında yetiştirilen toplam sebze üretimi 7.814.543 tondur. Mersin, 2.357.381 ton örtü altı sebze üretimi ile Türkiye'nin en önde gelen illerinden biri konumundadir (TÜİK, 2020). Araştırma kapsamına alınan sebzeler ise Mersin'de en fazla yetiştiriciliği yapılan örtü alt sebzelerdir. Emek ve bilgi isteği yoğun olan örtü altı tarımı, oluşturduğu istihdam olanakları ile de Mersin için önemli bir geçim kaynağ 1 durumundadır. $\mathrm{Bu}$ sebeple, örtü altı tarımında yetiştirilen başlıca ürünlerin maliyetlerinin ve kârlılıklarının hesaplanması bölge için yapılacak planlamalar başta olmak üzere pazarlama ağının geliştirilmesi, bölge tarımının yatay ve dikey entegrasyonunun sağlanması için alınabilecek önlemlerin geliştirilmesi gibi ekonomik ve sosyal politikalara yol gösterici olabilir.

Dengeli bir beslenme için vazgeçilmez bir gereklilik olan sebze üretiminde, kaynakların etkin kullanımının sağlanabilmesi hem tüketici hem üreticiler açısından önemlidir. Tarımsal verimliliği artırmak ve/veya girdi kullanımının optimizasyonu için kaynakların ne derece etkin kullanıldığının belirlenmesi gerekmektedir. Bu konuda yapılması gereken 
en önemli çalışmalardan biri ise, bölgelere göre üretim maliyetlerinin ve kârlılıklarının ortaya konulmasıdır. Türk tarımı genel olarak incelendiğinde, yaş meyve ve sebze üretiminde üretim planlaması eksiklikleri, girdi fiyatlarındaki dalgalanmalar, uluslararası standartlara göre dereceleme ve standardizasyon eksiklikleri, diş talepte yaşanan dalgalanmalar, etkin bir pazarlama ağının kurulamamış olması, çiftçilerin yeterince örgütlü hareket edememesi gibi temel problemlerin yaşandığ1 görülmektedir (Adanacıoğlu ve ark, 2019; Kazak ve ark, 2018; Özkan, 2016; Uysal and Cinemre, 2013). Bu sorunların ekonomik hayata yansıması, çiftçiler açısından maliyet, tüketiciler açısından ise yüksek fiyat şeklinde olmaktadır. $\mathrm{Bu}$ durum, tarımsal ürünlerde maliyet ve kârlılık analizlerinin önemini göstermektedir. Tarımsal üretimde maliyet ve kârlılıkla ilgili ve bu çalışmada da yararlanılan bazı çalışmalar aşağıda özetlenmiştir.

Aydoğan ve ark. (2020), çalışmalarında Samsun İli Vezirköprü İlçesinden kenevir üretiminin maliyet ve kârlılığını belirlemişılerdir. Araştırma sonuçlarına göre soyulmamış sap maliyet ortalama $1,8 \mathrm{TL} / \mathrm{kg}$, tohum maliyet $30,00 \mathrm{TL} / \mathrm{kg}$ ve lif maliyet $22,80 \mathrm{TL} / \mathrm{kg}$ olarak tespit edilmiştir. Ayrıca kenevir üretiminde toplam masrafların \%90,60'ının değişken masraflardan, \%9,40'ının ise sabit masraflardan oluştuğu bildirilmiştir. Hasat sonrası lif elde etme işlemlerinin bu amaca yönelik geliştirilmiş makineler ile yapılması durumunda lif maliyetlerinin \%34,60 oranında azaldığı ortaya konulmuştur.

Choudhary et al., (2017) Hindistan'da yürüttükleri çalışmalarında bezelye, lahana, fransız fasulyesi ve domates için karlılık analizleri yapmışlardır. Araştırmada her bir sebze için maliyetler ve getiriler analiz edilmiş ve bezelye, lahana, domates, fransiz fasulyesinin nispi karı sırasıyla 1,56, 1,25, 1,20 ve 1,10 olarak bildirilmiştir.

Hasan et al., (2014) Bangladeş'de yaptıkları çalışmalarında bazı önemli sebzeler için fayda-maliyet oranlarını hesaplanmışlardır. Araştırmada değişken maliyeti dikkate alan fayda-maliyet oranları, kabak, brinjal ve salatalık için sırasıyla 2,83, 4,88 ve 4,57 olarak bildirilmiştir. Ayrıca araştırmada, Bangladeş’te sebze yetiştiriciliğinin önündeki en önemli engeller sermaye eksikliği, sebzelerin düşük fiyat1, girdilerin yüksek fiyat1, fiyat dalgalanması, hastalık, girdinin kıtlığı ve depolama tesislerinin eksikliği olarak tespit edilmiştir.

Semerci ve ark. (2014) çalışmalarında, Hatay İlinde süt sığırı yetiştiren işletmelerin brüt kâr analizlerini yapmışlardır. İncelenen işletmelerde bir üretim dönemi için sağılan inek başına değişken masraflar 1.568 \$, brüt kâr 2.984 \$ ve $1 \mathrm{~kg}$ sütten elde edilen brüt kâr 0,53 \$ olarak bulunmuştur.

Semerci ve Çelik (2019) araştırmalarında, Hatay İlinde pamuk üretiminin ekonomik analizini yapmışlardır. Araştırmada pamuk üretim maliyeti 538,46 \$/ton olarak hesaplanmıştır. Ayrıca araştırmada tarımsal destekleme ödemelerinin, pamuğun brüt kâr, net kâr ve nispi kârları üzerine önemli derecede etki ettiği bildirilmiştir. 
Engindeniz ve Çukur (2003) araştırmalarında İzmir ilinde şeftali üretiminin maliyet ve kârlılık göstergelerini hesaplamışlardır. Araştırma sonuçlarına göre şeftali üretiminin, üretim dönemi masrafı ortalama 396,16 TL/da, net gelir $85.35 \mathrm{TL} / \mathrm{da}$, ağaç başına düşen net gelir ise 1,91 TL olarak bildirilmiştir.

\section{MATERYAL VE YÖNTEM}

Bu araştırmanın ana materyalini Tarım ve Orman Bakanlığı Mersin İl Müdürlüğü’nden elde edilen ikincil veriler oluşturmaktadır. Araştırmanın amaçlarına uygun olarak örtü altında üretilen önemli sebzelere ait, 2019 üretim dönemine ait, il ortalamasını yansıtan maliyet, verim ve fiyat verileri Tarım ve Orman Bakanlığı Mersin İl Müdürlüğü kayıtlarından elde edilmiştir (Anonim, 2020). Ayrica konu ile ilgili daha önce yapılmış çalışmalar ile çeşitli kurum ve kuruluşların istatistik ve diğer yayınlarından da yararlanılmıştır.

Araştırma kapsamında örtü altında gerçekleştirilen domates, biber, patlıcan, hıyar, kabak ve fasulyenin üretimine ilişkin gayrisafi üretim değerleri, net kâr, brüt kâr ve nispi kâr değerleri hesaplanmıştır. Gayri safi üretim değeri, verim ile satış fiyatının çarpımı; brüt kar, GSÜD'nden toplam değişken masrafların çıkarılması, net kar, GSÜD'nden toplam üretim masrafların çıkarılması ve nispi kar ise GSÜD'nin toplam üretim masraflarına bölünmesiyle hesaplanmıştır (İnan, 2006).

İncelenen ürünler için değişken masraflar, sabit masraflar ve toplam masraflar aşağıdaki kalemlerden oluşmaktadır:

- Değişken masraflar; sürüm giderleri, çizgi çekme (masura açma), fide dikimi ve bedeli, can suyu, kaymak kırma-kök kabartma, çapalama-ot alma, sulama ve işçiliği, zirai mücadele ve işçiliği, çiftlik gübresi, suni gübre ve gübreleme işçiliği, hasat (makine veya elle), nakliyepazarlama,

- Sabit masraflar ${ }^{1}$; bilinmeyen masraflar, idarecilik gideri ve tarımsal kredi faizi

- Toplam masraflar; değişken ve sabit masrafların toplamıdır.

\section{ARAŞTIRMA BULGULARI VE TARTIŞMA}

\subsection{Türkiye'de araştırma kapsamına alınan sebzelerin üretimi}

Türkiye ekolojik ve iklim koşulları sayesinde bir çok sebze ve meyvenin üretiminde avantajlı bir konumdadır. Tarım sektörü içerisinde yaş meyve ve sebze sektörü, önemli altı sektörlerden biridir. Türkiye'nin örtü altı sebze üretiminde domates ilk sırayı almaktadır. Yeterlik oranı \%100’ün üzerinde olan domates (TÜİK, 2020) 2019 y1lı itibariyle 4 milyon tonu aşan üretim hacmiyle, Türkiye'de en fazla örtü altı yetiştiriciliği yapılan üründür. Türkiye'de 2015 y1lında toplam domates üretimi yaklaşık 3,4 milyon ton olup, 2019 yılına gelindiğinde \%20,30'luk artış ile yaklaşık 4,01 1 Ara toplama \%10 bilinmeyen masraflar (amortisman, vergi, stopaj, kira, sigorta vb. gibi), \%3 idarecilik masrafları (üretim değerinin \%3’ü) ve zirai sermaye faizi (T.C. Ziraat Bankası tarımsal kredi faizi; tek yıllık bitkilerde 6 aylık, çok yıllık bitkilerde 12 aylık) eklenmek suretiyle toplam maliyet bulunur. 
milyon ton olmuştur. Aynı dönemde Mersin'de gerçekleştirilen domates üretimi de benzer şekilde \%19,17 artış göstermiştir. Tıpkı üretim miktarı gibi örtü altı üretim alanı da 2015-2019 döneminde hem Türkiye'de hem Mersin'de düzenli bir artış göstermiştir. Aynı dönemde örtü altı sivri biber üretimi hem Türkiye'de hem Mersin'de az bir düşüş göstermiş; Mersin'de üretim alanlarının yaklaşık \%1 azalmasına karşın üretim miktarı \% 7,64 oranında artmıștır. Bu durum Mersin'de sivri biber üretiminde girdi kullanım etkinliğinin iyileştiğinin ve/veya teknik ilerleme gerçekleştiğinin göstergesi olabilir. Tıpkı domates gibi sivri biberde de Türkiye'nin yeterlik oranı \%100'ün üzerindedir (Çizelge 1). 2015-2019 döneminde örtü altı hıyar ve patlıcan üretimi hem Türkiye genelinde ve hem de Mersin'de artış göstermiştir. Türkiye'de 2015 yılında hıyar üretimi yaklaşık 1,08 milyon ton iken, 2019 yılında \%7,11 oranında artış göstermiştir. Mersin İlinin hıyar üretimi de aynı dönemde \% 23,34 oranında artmıştır. Türkiye’nin patlican üretimi ise 2015 - 2019 döneminde \% 29,04 oranında artış, Mersin İlinde bu oran ise \% 31,60 seviyesinde gerçeklemiştir (Çizelge 2). Türkiye'nin yeterlik derecesi her iki üründe de \%100’ün üzerindedir (TÜİK, 2020).

Türkiye'nin yeterlik derecesi \%100'ün üzerinde olan örtü altı fasulye ve kabak üretimi, 20152019 döneminde hem Türkiye'de ve hem de Mersin'de artış göstermiştir. Türkiye'de 2015 y1lında toplam 39.049 da alandan fasulye üretimi gerçekleştirilirken, 2019 yılında fasulye üretim alanı \%24,81 oranında artış ile 59.293 olarak gerçekleşmiştir. $\mathrm{Bu}$ artışa paralel olarak Mersin'de de aynı dönemde fasulye üretim alanları \%19,49 oranında artmıştır. 2015-2019 yılları arasında, hem üretim alanı ve hem de verimlilik artışı ile Türkiye ve Mersin'de fasulye üretim miktarı, üretim alanlarından daha fazla oranda artış göstermiştir. Ele alınan diğer ürünler gibi kabak üretimi de, 2015-2019 döneminde hem Türkiye ve hem de Mersin'de artış göstermiştir. 2015-2019 döneminde Türkiye'de kabak üretim

Çizelge 1. Türkiye'de ve Mersin'de örtü altı domates ve sivri biber üretimi

\begin{tabular}{|c|c|c|c|c|c|c|c|c|}
\hline \multirow{3}{*}{$\begin{array}{l}\text { Ürün } \\
\text { Yıllar }\end{array}$} & \multicolumn{4}{|c|}{ Domates } & \multicolumn{4}{|c|}{ Sivri Biber } \\
\hline & \multicolumn{2}{|c|}{ Mersin } & \multicolumn{2}{|c|}{ Türkiye } & \multicolumn{2}{|c|}{ Mersin } & \multicolumn{2}{|c|}{ Türkiye } \\
\hline & $\begin{array}{c}\text { Alan } \\
\text { (da) }\end{array}$ & $\begin{array}{c}\text { Üretim } \\
\text { (ton) }\end{array}$ & $\begin{array}{c}\text { Alan } \\
\text { (da) }\end{array}$ & Üretim (ton) & $\begin{array}{c}\text { Alan } \\
\text { (da) }\end{array}$ & $\begin{array}{c}\text { Üretim } \\
\text { (ton) }\end{array}$ & $\begin{array}{c}\text { Alan } \\
\text { (da) }\end{array}$ & $\begin{array}{c}\text { Üretim } \\
\text { (ton) }\end{array}$ \\
\hline 2015 & 25.937 & 341.432 & 258.031 & 3.394 .447 & 29.531 & 190.111 & 51.804 & 385.548 \\
\hline 2016 & 25.797 & 344.441 & 273.228 & 3.614 .472 & 29.531 & 199.806 & 53.857 & 414.058 \\
\hline 2017 & 26.852 & 404.555 & 281.476 & 3.829 .831 & 28.568 & 198.818 & 52.596 & 394.756 \\
\hline 2018 & 28.905 & 394.268 & 280.805 & 3.888 .555 & 28.845 & 201.018 & 51.847 & 382.029 \\
\hline 2019 & 29.652 & 406.880 & 293.775 & 4.083 .681 & 29.245 & 204.642 & 48.874 & 367.224 \\
\hline
\end{tabular}

Kaynak: TÜİK (2020) 
Çizelge 2. Türkiye'de ve Mersin'de örtü altı hıyar ve patlıcan üretimi

\begin{tabular}{|c|c|c|c|c|c|c|c|c|}
\hline \multirow{3}{*}{$\begin{array}{l}\text { Ürün } \\
\text { Yillar }\end{array}$} & \multicolumn{4}{|c|}{ Hiyar } & \multicolumn{4}{|c|}{ Patlican } \\
\hline & \multicolumn{2}{|c|}{ Mersin } & \multirow{2}{*}{$\begin{array}{c}\text { Türkiye } \\
\text { Alan } \\
\text { (da) }\end{array}$} & \multirow[b]{2}{*}{$\begin{array}{l}\text { Üretim } \\
\text { (ton) }\end{array}$} & \multicolumn{2}{|c|}{ Mersin } & \multicolumn{2}{|c|}{ Türkiye } \\
\hline & $\begin{array}{c}\text { Alan } \\
\text { (da) }\end{array}$ & $\begin{array}{l}\text { Üretim } \\
\text { (ton) }\end{array}$ & & & $\begin{array}{c}\text { Alan } \\
\text { (da) }\end{array}$ & $\begin{array}{c}\text { Üretim } \\
\text { (ton) }\end{array}$ & $\begin{array}{l}\text { Alan } \\
\text { (da) }\end{array}$ & $\begin{array}{l}\text { Üretim } \\
\text { (ton) }\end{array}$ \\
\hline 2015 & 14.269 & 173.892 & 81.302 & 1.080 .213 & 10.441 & 74.290 & 30.198 & 250.311 \\
\hline 2016 & 14.283 & 185.135 & 79.919 & 1.077 .783 & 10.611 & 98.306 & 31.963 & 291.314 \\
\hline 2017 & 17.794 & 213.865 & 84.281 & 1.121 .625 & 11.910 & 119.005 & 36.315 & 344.620 \\
\hline 2018 & 17.002 & 214.993 & 84.199 & 1.134 .182 & 11.009 & 113.156 & 33.986 & 332.742 \\
\hline 2019 & 16.969 & 214.471 & 85.133 & 1.156 .997 & 9.633 & 97.769 & 33.211 & 323.009 \\
\hline
\end{tabular}

Kaynak: TÜİK (2020)

alanlarındaki artış \%23,30, üretim miktarındaki artış da \%74,81 olmuştur. Mersin'de de aynı dönemde kabak üretim alanı \%98,80 oranında artarken, üretim miktarındaki artış \%264,21 olmuştur.

\subsection{Araştırma kapsamına alınan sebzelerde} maliyet ve kârlılık analizi
Bu araştırmada, Mersin İlinde örtü altı üretiminde önemli bir yer tutan domates, biber, patlican, hıyar, kabak ve fasulye sebzelerine ilişkin maliyet ve kârlılık değerleri hesaplanmıştır. Araştırma sonuçlarına göre, en düşük birim maliyet domates üretiminde $(0,81 \mathrm{TL} / \mathrm{kg})$, en yüksek birim maliyet ise biber üretiminde $(3,06 \mathrm{TL} / \mathrm{kg})$ gerçekleşmiştir. Üretim miktarına bağlı olarak artış ya da azalış gösteren değişen masraflar ise

Çizelge 3. Türkiye'de ve Mersin'de örtü altı fasulye ve kabak üretimi

\begin{tabular}{|c|c|c|c|c|c|c|c|c|}
\hline \multirow{3}{*}{$\begin{array}{l}\text { Ürün } \\
\text { Yıllar }\end{array}$} & \multicolumn{4}{|c|}{ Fasulye (Taze) } & \multicolumn{4}{|c|}{ Kabak (Sakız) } \\
\hline & \multicolumn{2}{|c|}{ Mersin } & \multicolumn{2}{|l|}{ Türkiye } & \multicolumn{2}{|c|}{ Mersin } & \multicolumn{2}{|c|}{ Türkiye } \\
\hline & $\begin{array}{c}\text { Alan } \\
\text { (da) }\end{array}$ & $\begin{array}{c}\text { Üretim } \\
\text { (ton) }\end{array}$ & Alan (da) & $\begin{array}{c}\text { Üretim } \\
\text { (ton) }\end{array}$ & $\begin{array}{c}\text { Alan } \\
\text { (da) }\end{array}$ & $\begin{array}{c}\text { Üretim } \\
\text { (ton) }\end{array}$ & $\begin{array}{c}\text { Alan } \\
\text { (da) }\end{array}$ & $\begin{array}{c}\text { Üretim } \\
\text { (ton) }\end{array}$ \\
\hline 2015 & 1.693 & 2.017 & 13.236 & 39.049 & 5.959 & 34.781 & 22.425 & 121.250 \\
\hline 2016 & 1.713 & 3.212 & 13.622 & 45.879 & 6.259 & 53.612 & 23.481 & 143.150 \\
\hline 2017 & 2.035 & 3.600 & 14.415 & 47.936 & 14.552 & 126.046 & 31.797 & 219.304 \\
\hline 2018 & 2.031 & 3.598 & 16.102 & 57.421 & 13.959 & 153.751 & 30.464 & 242.218 \\
\hline 2019 & 2.023 & 3.606 & 16.520 & 59.293 & 11.489 & 126.676 & 27.650 & 211.953 \\
\hline
\end{tabular}

Kaynak: TÜİK (2020) 
Çizelge 4. Araştırma kapsamına alınan sebzelerin maliyet ve kârlılık değerleri

\begin{tabular}{|l|r|r|r|r|r|r|}
\hline \multicolumn{1}{|c|}{ Göstergeler } & \multicolumn{7}{c|}{ Ürünler } \\
& Domates & \multicolumn{1}{c|}{ Biber } & Patlıcan & \multicolumn{1}{l|}{ Hıyar } & Kabak & \multicolumn{1}{l|}{ Fasulye } \\
\hline DM (TL/da) & $8.409,24$ & $8.713,55$ & $7.535,37$ & $8.241,54$ & $7.309,95$ & $4.390,15$ \\
\hline SM (TL/da) & $1.324,46$ & $1.612,01$ & $1.394,05$ & $1.524,69$ & $3.015,61$ & $3.012,18$ \\
\hline TM (TL/da) & $9.733,70$ & $10.325,56$ & $8.929,42$ & $9.766,23$ & $10.325,56$ & $7.402,33$ \\
\hline Verim (kg/da) & $12.000,00$ & $3.375,00$ & $5.000,00$ & $11.150,00$ & $5.000,00$ & $7.000,00$ \\
\hline BM (TL/kg) & 0,81 & 3,06 & 1,79 & 0,88 & 2,07 & 1,06 \\
\hline Fiyat (TL/kg) & 2,83 & 5,19 & 2,52 & 1,76 & 2,52 & 3,78 \\
\hline GSÜD (TL/da) & $33.960,00$ & $17.499,38$ & $12.600,00$ & $19.624,00$ & $12.600,00$ & $26.425,00$ \\
\hline Brüt Kâr (TL/da) & $25.550,76$ & $8.785,83$ & $5.064,63$ & $11.382,46$ & $5.290,05$ & $22.034,85$ \\
\hline Net Kâr (TL/da) & $24.226,30$ & $7.173,82$ & $3.670,58$ & $9.857,77$ & $2.274,44$ & $19.022,67$ \\
\hline Nispi Kâr & 3,49 & 1,69 & 1,41 & 2,01 & 1,22 & 3,57 \\
\hline DM: Değ & & & & &
\end{tabular}

DM: Değişen masraflar, SM: Sabit masraflar, TM: Toplam masraflar, BM: Birim masraflar, GSÜD: Gayrisafi üretim değeri

en fazla biber üretiminde $(8.713,55 \mathrm{TL} / \mathrm{da})$, en düşük ise fasulye üretiminde $(4.390,15 \mathrm{TL} / \mathrm{da})$ belirlenmiştir. Toplam masraflarda da benzer bir durum gözlenmiştir. En yüksek toplam masraf biber üretiminde (10.325,56 TL/da), en düşük de fasulye üretiminde $(7.402,33 \mathrm{TL} / \mathrm{da})$ görülmüştür (Çizelge 2). Araştırma kapsamına alınan sebzelerde değişken masrafların toplam masraflar içerisindeki oranı $\% 60,00$ ile $\% 86,00$ arasında değiş̧mektedir. Bunun yanı sıra ele alınan sebzelerde işgücü masrafları toplam masraflar içerisinde en yüksek orana sahip masraf kalemi olarak gözlenmektedir. İncelenen ürünlerde en yüksek GSÜD domates üretiminde (33.960,00 TL/da), en düşük GSÜD ise kabak üretiminde (12.600,00 TL/da) gerçekleşmiştir.

GSÜD'den değişken masrafların çıkarılmasıyla hesaplanan brüt kâr, üretim faaliyetlerinin karşılaştırılmasında kullanılan önemli bir ölçüttür. Buna göre en yüksek brüt kâr domates üretiminden $(25.550,76 \mathrm{TL} / \mathrm{da})$, en düşük brüt kâr ise patlıcan üretiminden $(5.064,63 \mathrm{TL} / \mathrm{da})$ elde edilmiştir. Brüt kârın GSÜD'ye oranı en yüksek fasulye üretiminde $(\% 83,39)$, en düşük ise kabak üretiminde $(\% 41,98)$ hesaplanmıştır. Bir üretim faaliyetinin GSÜD'den toplam masrafların çıkarılmasıyla elde edilen net kâr, ekonomik kârı daha iyi birşekilde yansıtmaktadır. İncelenen sebzelerde net kâr, en yüksek domates üretiminden, en düşük ise patlıcan üretiminden elde edilmektedir. Nispi kâr çiftçinin 1 TL'lik masrafa karşıllk, ne kadar gelir elde ettiğini göstermektedir. İncelenen sebzelerin tamamında nispi kâr 1'in üzerindedir. En yüksek nispi kâr fasulyede $(3,57)$ gözlenirken, onu sirasiyla 
domates $(3,49)$, hiyar $(2,01)$, biber $(1,69)$, patlican $(1,41)$ ve kabak $(1,22)$ izlemektedir (Çizelge 4). Bangladeş’te hıyar üretiminde nispi kar 2,40 (Hasan et al, 2014), Hindistan'da domates üretimde 1,20, fasulye üretiminde 1,10 olarak (Choudhary et al, 2017) olarak bildirilmiştir.

\section{SONUÇ}

Bu çalışmada, tarımsal ürün fiyat oluşumunun en önemli unsuru olması nedeniyle, Mersin'de örtü altından yaygın olarak yetiştirilen sebzelerin maliyet ve kârlılıklarının analizi yapılmıştır. $\mathrm{Bu}$ amaçla, 2019 yılına ait, Tarım ve Orman Bakanlığı Mersin İl Müdürlüğü kayıtlarından elde edilen girdi maliyetleri, ortalama verim ve ortalama fiyat verilerinden yararlanılarak örtü altından yetiştirilen domates, biber, patlıcan, hiyar, kabak, fasulyenin GSÜD, brüt kâr, net kâr ve nispi kâr değerleri hesaplanmıştır. İncelenen ürünler arasında, en düşük birim maliyet domates, en yüksek ise biber üretiminde gerçekleşmiştir. En düşük değişken masraf ise fasulye, en yüksek biber üretiminde gözlenmiştir. Toplam masraflar içerisinde değişken masrafların oranı incelenen ürünler itibariyle oldukça yüksektir. İncelenen ürünlerin kârlılık analizlerine göre, en yüksek GSÜD domates, en düşük ise patlican ve kabak üretiminde gerçekleşmiştir. Hem brüt kârı ve hem net kârı en yüksek olan ürün domatestir. Nispi kâr ise incelenen ürünlerin tamamında 1'den büyüktür.

Bölgede ve Türkiye genelinde maliyet ve kârlılık analizlerinin uygun üretim faaliyetleri arasında seçim yapmak ve kaynakları etkin kullanmak için yol gösterici olacağı düşünülmektedir. Ele alınan ürünlerin tamamında, Türkiye' nin yeterlik derecesinin 1'in üzerinde olması nedeniyle, bu ürünlerin üretiminin plansız bir şekilde artması halinde ciddi fiyat dalgalanmaları yaşanabilir. $\mathrm{Bu}$ ürünlerin, üretim miktarlarının artırılmasına ve bu ürünlerin yetiştiriciliğinin yaygınlaştırılmasına yönelik alınacak önlemlerde, piyasa talebindeki olası değişiklikler, ilgili tarımsal ve gıda sanayinin durumu ve ihracat olanakları göz önüne alınmalıdır. Ayrıca, incelenen ürünlerde daha sonra yapılacak çalışmaların, üretim miktarının artırılmasından çok, girdi kullanımında tasarruf sağlayacak önlemlere odaklanması daha uygun olacaktır. Özellikle hastalık ve zararlılara karşı alınacak önlemler ile tarımsal ilaç kullanımının önüne geçilmesi çiftçi gelirinin artıracak sonuçlar verebilir.

\section{Kaynaklar}

Adanacıŏlu, H., Kınıklı, F., Gizem, Ö., ve Y1lmaz, C. (2019). Komisyoncuların Hal Kayıt Sisteminin etkinliği hakkındaki görüşleri: İzmir ili yaş sebze ve meyve toptanc1 hali örneği. Mediterranean Agricultural Sciences 32, 335-341.

Anonim (2020). Tarım ve Orman Bakanlığg Mersin İl Müdürlüğü kayıtları.

Aydoğan, M., Terzi, Y. E., Gizlenci, Ş., Acar, M., Alpar, E., ve Meral, H. (2020). Türkiye'de kenevir yetiştiriciliğinin ekonomik olarak yapılabilirliği: Samsun ili Vezirköprü ilçesi örneği. Anadolu Tarım Bilimleri Dergisi 35, 35-50. 
Choudhary, H., Bisht, D., Badal, P. S., Singh, V., Shah, R., and Saryam, M. (2017). Profitability of Vegetables in Hill Agriculture: An Economic Analysis. International Journal of Current Microbiology and Applied Sciences, 6(8), 1674-1682.

Dinler, Z. (2014). “Tarım ekonomisi (Yedinci baskı)," Ekin Basım Yayım ve Dağıtım, Bursa.

Engindeniz, S., ve Çukur, F. (2003). İzmir ili Kemalpaşa ilçesinde şeftali üretiminin teknik ve ekonomik analizi üzerine bir araştırma. Ege Üniversitesi Ziraat Fakültesi Dergisi 40, 65-72.

Hasan, M. R., Bai, D. H., and Islam, M. A. (2014). Profitability of important summer vegetables in Keranigoni upazilla of Bangladesh. Journal of the Bangladesh Agricultural University, 12(452-201635623), 111-118.

İnan,İ.H.(2006). Tarımekonomisiveişletmeciliği (Genişletilmiş ve güncellenmiş altıncı baskı), Hasad Yayıncılık, Tekirdağ.

Kazak, G., Özşenler, S., Artukoğlu, M. M., ve Y1ldiz, Ö. (2018). Sanayi Domatesi Üretimi ve Pazarlamasında Karşılaşılan Sorunlar: Torbalı İlçesi Örneği. Tarım Ekonomisi Dergisi 24, 215-223.

Kıral, T., Kasnakoğlu, H., Tatlıdil, F., Fidan, H., ve Gündoğmuş, E. (1999). “Tarımsal ürünler için maliyet hesaplama metodolojisi ve veri tabanı rehberi.," Tarımsal Ekonomi Araştırma Enstitüsü, Ankara.

Özkan, A. (2016). Türkiye tarımında yaşanan sorunlar ve alternatif tarımsal üretim anlayışlarının değerlendirilmesi. Balıkesir Üniversitesi Sosyal Bilimler Enstitüsü Dergisi 19, 411-430.

Semerci, A., ve Çelik, A. D. (2019). Türkiye'de Pamuk Üretiminin Ekonomik Analizi: Hatay İli Örneği. Turkish Journal of Agriculture-Food Science and Technology 7, 246-252.

Semerci, A., Parlakay, O., and Çelik, A. D. (2014). Gross margin analysis in dairy cattle: a case study of Hatay Province, Turkey. Custos e@gronegócio on line 10, 154-170.

TÜİK (2020). http://www.tuik.gov.tr/ (Erişim: 15/02/2020).

Uysal, O., and Cinemre, H. A. (2013). A research on determination of the optimal production plans in the district of Dikbiyik in Samsun Province. Anadolu Tarım Bilimleri Dergisi 28, 1-9. 